MATEC Web of Conferences 34, 05005 (2015)

DOI: $10.1051 /$ matecconf/ 20153405005

(c) Owned by the authors, published by EDP Sciences, 2015

\title{
Ho Loop Shaping Robust Control For Tractor-semitrailer
}

\author{
Sheng Chang ${ }^{1, a}$, Ling-ling Chen ${ }^{1}$, Jin-feng $\mathrm{Wu}^{2}$, Nai-wei Zou ${ }^{1}$ \\ 1 Jiamusi University in Heilongjiang, China \\ 2 Chang'an University in Shanxi, China
}

\begin{abstract}
The tractor-semitrailer model is general described and analyzed in road reference coordinate system. The lateral error of look-ahead distance has been chosen as nominal plant and a robust controller using $H_{\infty}$ loop-shaping procedure is designed which can ensure the maximum stability margin meet the performance requirements. The results show that the controller can make the tractor-semitrailer stable under perturbed conditions and can guarantee the look-ahead lateral offset keeping in the specified scope proposed. The target of lateral control is satisfactory.
\end{abstract}

\section{Introduction}

When the Tractor-semitrailer meets interference on the road, lateral displacement will increase without limited by time. So, it is necessary to do some manipulations to insure that vehicle system can travel by planned routes. The author [1] has designed $H_{\infty}$ loop-shaping robust controller to study the tractor-semitrailer response in straight line when the vehicle subjected interference by the lateral force, although the study ends up with good results but it dose not take control for the generalized description vehicle model. WANG [2] make use of this control method to study the vehicle steering, but the degree of freedom (DOF) of body roll in vehicle model is not considered. For previous study, this paper will work further more and be organized as follows. First of all, in order to realize the targets of the control for interference and the tracking output, tractor-semitrailer model which include DOF of body roll will be described in road reference coordinate system as generalized controlled object; Secondly, $H_{\infty}$ loop-shaping robust controller will be designed and the order of the controller will be reduced; Finally, path tracking control of tractorsemitrailer will be simulated.

\section{Analyses of tractor-semitrailer model in road reference coordinate system}

\subsection{Describe of generalized controlled object}

In road reference coordinate system, $X_{r}$-axis direction is tangential direction of drive line. $Y_{r}$-axis direction is vertical with $X_{r}$-axis and goes through the center of mass of tractor, $Z_{r}$-axis direction is vertical with $X_{r}-Y_{r}$ plane and it pointing upwards. Symbol $y_{r 1}$ represents the distance between the center of mass of tractor and the center line of the road in the $Y_{r}$-axis direction. Lookahead distance is $d$ in the direction of $X_{r}$, lateral displacement of its observation point to target line is $Y_{d}$, just show in Figure 1. Parameters are given in Table 1.

Table 1. Parameters values of tractor-semitrailer

\begin{tabular}{|c|c|}
\hline Symbol & Parameter name, value and unit \\
\hline$m_{\mathrm{s} 1}$ & sprung mass of tractor $(6308 \mathrm{~kg})$ \\
\hline$m_{\mathrm{u} 1}$ & unsprung mass of tractor $(2504 \mathrm{~kg})$ \\
\hline$m_{1}$ & tractor mass $(8812 \mathrm{~kg})$ \\
\hline$a_{1}$ & $\begin{array}{l}\text { the distance between tractor front axle to } \\
\text { tractor vehicle center }(2.804 \mathrm{~m})\end{array}$ \\
\hline$b_{1}$ & $\begin{array}{l}\text { the distance between tractor rear axle to the } \\
\text { towing vehicle center }(2.485 \mathrm{~m})\end{array}$ \\
\hline$c$ & $\begin{array}{l}\text { the distance between traction point to } \\
\text { tractor center }(1.985 \mathrm{~m})\end{array}$ \\
\hline$C_{f}$ & $\begin{array}{l}\text { the total cornering stiffness of tractor } \\
\text { wheel }(430.6682 \mathrm{kN} / \mathrm{rad})\end{array}$ \\
\hline$I_{x s 1}$ & $\begin{array}{l}\text { inertia that tractor sprung mass spins around } \\
\text { the } x \text {-axis }\left(6879 \mathrm{~kg} \cdot \mathrm{m}^{2}\right)\end{array}$ \\
\hline$I_{z 1}$ & $\begin{array}{l}\text { inertia that tractor vehicle spins around the } \\
\mathrm{z} \text {-axis }\left(20277 \mathrm{~kg} \cdot \mathrm{m}^{2}\right)\end{array}$ \\
\hline$I_{x z 1}$ & $\begin{array}{l}\text { inertia that tractor sprung mass turns around } \\
\mathrm{x} \text { and } \mathrm{z} \text { axis }\left(130 \mathrm{~kg} \cdot \mathrm{m}^{2}\right)\end{array}$ \\
\hline$h_{s 1}$ & the distance between roll center $(0.519 \mathrm{~m})$ \\
\hline$D_{f}$ & $\begin{array}{l}\text { roll angle damping of front suspension of } \\
\text { tractor }(2866.24 \mathrm{~N} \cdot \mathrm{m} \cdot \mathrm{s} / \mathrm{rad})\end{array}$ \\
\hline$D_{t}$ & $\begin{array}{l}\text { roll angle damping of rear suspension of } \\
\text { trailer }(5732.48 \mathrm{~N} \cdot \mathrm{m} \cdot \mathrm{s} / \mathrm{rad})\end{array}$ \\
\hline$C_{\varphi r}$ & $\begin{array}{l}\text { roll rate of rear of suspension of trailer } \\
\text { tractor }(28662.4 \mathrm{~N} \cdot \mathrm{m} / \mathrm{rad})\end{array}$ \\
\hline$E_{f}$ & tilt steering coefficient of tractor $\left(-0.21^{\circ}{ }^{\circ}\right)$ \\
\hline$E_{t}$ & shift factor of roll for trailer rear $\left(-0.17^{\circ} /{ }^{\circ}\right)$ \\
\hline$C_{s}$ & $\begin{array}{l}\text { damping of Steering wheel around } \\
\text { kingpin }(600 \mathrm{~N} \cdot \mathrm{m} \cdot \mathrm{s} / \mathrm{rad})\end{array}$ \\
\hline
\end{tabular}

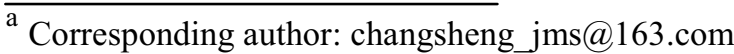




\begin{tabular}{|c|c|}
\hline$i$ & ratio of transmission of steering system(25) \\
\hline$m_{\mathrm{s} 2}$ & sprung mass of trailer $(5927 \mathrm{~kg})$ \\
\hline$m_{\mathrm{u} 2}$ & unsprung mass of trailer $(1470 \mathrm{~kg})$ \\
\hline$m_{2}$ & trailer mass $(7397 \mathrm{~kg})$ \\
\hline$a_{2}$ & $\begin{array}{l}\text { the distance between traction point to trailer } \\
\text { vehicle center }(8.588 \mathrm{~m})\end{array}$ \\
\hline$b_{2}$ & $\begin{array}{l}\text { the distance between trailer axle to a semi- } \\
\text { trailer vehicle center }(5.180 \mathrm{~m})\end{array}$ \\
\hline$C_{t}$ & $\begin{array}{l}\text { cornering stiffness of trailer rear } \\
(367.1652 \mathrm{kN} / \mathrm{rad})\end{array}$ \\
\hline$C_{r}$ & $\begin{array}{l}\text { the total cornering stiffness of trailer } \\
\text { wheel }(484.1082 \mathrm{kN} / \mathrm{rad})\end{array}$ \\
\hline$I_{x s 2}$ & $\begin{array}{l}\text { inertia that trailer sprung mass spins around } \\
\text { the } \mathrm{x}-\operatorname{axis}\left(9960 \mathrm{~kg} \cdot \mathrm{m}^{2}\right)\end{array}$ \\
\hline$I_{z 2}$ & $\begin{array}{l}\text { inertia that trailer vehicle spins around the } \mathrm{z} \text { - } \\
\operatorname{axis}\left(181171 \mathrm{~kg} \cdot \mathrm{m}^{2}\right)\end{array}$ \\
\hline$I_{x z 2}$ & $\begin{array}{l}\text { inertia that trailer sprung mass turns around } \\
\mathrm{x} \text { and } \mathrm{z} \text { axis }\left(0 \mathrm{~kg} \cdot \mathrm{m}^{2}\right)\end{array}$ \\
\hline$h_{s 2}$ & $\begin{array}{l}\text { the distance between tractor sprung mass } \\
\text { center and roll center }(1.061 \mathrm{~m})\end{array}$ \\
\hline$D_{r}$ & $\begin{array}{llll}\text { roll angle damping of } \operatorname{tractor}(2866.24 \\
\mathrm{N} \cdot \mathrm{m} \cdot \mathrm{s} / \mathrm{rad})\end{array}$ \\
\hline$C_{\varphi f}$ & $\begin{array}{l}\text { roll rate of front suspension of tractor } \\
(28662.4 \mathrm{~N} \cdot \mathrm{m} / \mathrm{rad})\end{array}$ \\
\hline$C_{\varphi t}$ & $\begin{array}{lcccc}\text { roll rate of rear suspension of } \\
(573248 \mathrm{~N} \cdot \mathrm{m} / \mathrm{rad})\end{array}$ \\
\hline$E_{r}$ & tilt steering coefficient of tractor $\left(0.11^{\circ} \%\right)$ \\
\hline$I_{s}$ & $\begin{array}{l}\text { inertia that tractor steering wheel turns } \\
\text { around kingpin }\left(0.8 \mathrm{~kg} \cdot \mathrm{m}^{2}\right)\end{array}$ \\
\hline$K_{s}$ & $\begin{array}{l}\text { comprehensive stiffness of steering } \\
\text { system }(20000 \mathrm{~N} \cdot \mathrm{m} / \mathrm{rad})\end{array}$ \\
\hline$\xi_{1}$ & $\begin{array}{l}\text { arm that front wheel lateral force to } \\
\text { kingpin }(0.05 \mathrm{~m})\end{array}$ \\
\hline
\end{tabular}

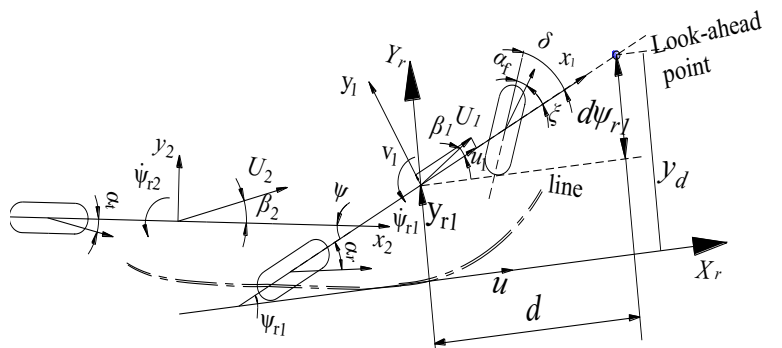

Figure 1. The movement of tractor-semitrailer along target lane

From Figure 1, as for tractor, longitudinal speed is represented by the symbol $u_{1}$, yaw angle is represented by the symbol $\psi_{r 1}$ and $\dot{\psi}_{r 1}$ represent yaw rate. So, the lateral acceleration of tractor in the direction of $y_{1}$ could express like Equation 1.

$$
\dot{v}_{1}=\ddot{y}_{r 1}-u_{1} \dot{\psi}_{r 1}
$$

To ensure $Y_{r}$ axis which through the center of mass of tractor is perpendicular to $X_{r}$ axis, it is necessary to assume coordinates of path to the moving coordinate system, you could know all coordinate system's relations in Figure 2.

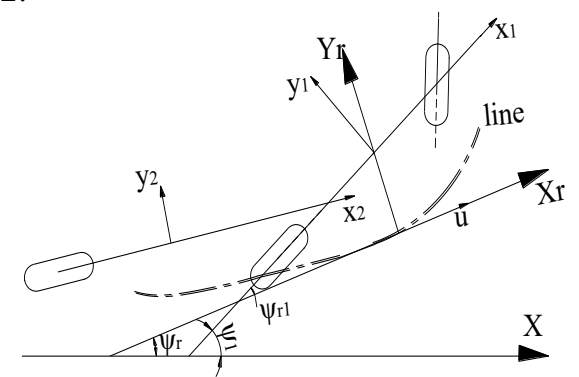

Figure 2. The relationship between fixed and road reference coordinate system

Yaw rate of tractor can be expressed as $\dot{\psi}_{1}$

$$
\dot{\psi}_{1}=\dot{\psi}_{r 1}+\dot{\psi}_{r}
$$

$\dot{\psi}_{r}$ is angular velocity that tractor should get in target line when it moves without deviation. Similarly

$$
\dot{\psi}_{2}=\dot{\psi}_{r 2}+\dot{\psi}_{r}
$$

From (2) and (3), $\dot{\psi}_{1}$ and $\dot{\psi}_{2}$ are tractor and trailer's raw rate $\dot{r}_{1}$ and $\dot{r}_{2}$ under the model of the vehicle's coordinate system in [6], using Eqution 1- Equation3, the state variables

$$
\left[\begin{array}{llllllllll}
\dot{v}_{1} & \dot{r}_{1} & \dot{r}_{2} & \dot{\psi} & \dot{p}_{1} & \dot{p}_{2} & \dot{\varphi}_{1} & \dot{\varphi}_{2} & \ddot{\delta} & \dot{\delta}
\end{array}\right]^{T}
$$

can be replaced by

$$
\left[\begin{array}{llllllllll}
\dot{y}_{r 1}-u_{1} \psi_{r 1} & \dot{\psi}_{r 1}+\dot{\psi}_{r} & \dot{\psi}_{r 2}+\dot{\psi}_{r} & \psi & p_{1} & p_{2} & \varphi_{1} & \varphi_{2} & \dot{\delta} & \delta
\end{array}\right]^{T}(5)
$$

Then, motion equations of tractor-semitrailer are written about $y_{r}(t)$ two order form

$\ddot{y}_{r}(t)+M^{-1} N \dot{y}_{r}(t)+M^{-1} P y_{r}(t)=M^{-1} Q \delta_{s w}+M^{-1} D_{1} \dot{\psi}_{r}(t)+M^{-1} D_{2} \ddot{\psi}_{r}(t)$

where

$$
\begin{aligned}
& x_{1}(t)=y_{r}(t)=\left[\begin{array}{lllllll}
y_{r 1} & \psi_{r 1} & \psi_{r 2} & \varphi_{1} & \varphi_{2} & \psi & \delta
\end{array}\right]^{T} \\
& x_{2}(t)=\dot{y}_{r}(t)=\left[\begin{array}{lllllll}
\dot{y}_{r 1} & \dot{\psi}_{r 1} & \dot{\psi}_{r 2} & \dot{\varphi}_{1} & \dot{\varphi}_{2} & \dot{\psi} & \dot{\delta}
\end{array}\right]^{T}
\end{aligned}
$$

so equations of motion express as

$\left[\begin{array}{l}\dot{x}_{1}(t) \\ \dot{x}_{2}(t)\end{array}\right]=\left[\begin{array}{cc}\boldsymbol{0} & \boldsymbol{I} \\ -M^{-1} P & -M^{-1} N\end{array}\right]\left[\begin{array}{l}x_{1}(t) \\ x_{2}(t)\end{array}\right]+\left[\begin{array}{l}\boldsymbol{0} \\ M^{-1} Q\end{array}\right] \delta_{s w}+\left[\begin{array}{l}\boldsymbol{0} \\ M^{-1} D_{1}\end{array}\right] \dot{\psi}_{r}+\left[\begin{array}{l}\boldsymbol{0} \\ M^{-1} D_{2}\end{array}\right] \ddot{\psi}_{r}$

In (9), $\boldsymbol{O}$ is 7-order zero matrix, $\boldsymbol{I}$ is 7-order unit matrix, which write as the form of generalized description

$$
\left[\begin{array}{c}
\dot{x} \\
z \\
y
\end{array}\right]=\left[\begin{array}{c:cc}
A & B_{1} & B_{2} \\
\hdashline C_{1} & D_{11} & D_{12} \\
C_{2} & D_{21} & D_{22}
\end{array}\right]\left[\begin{array}{c}
x \\
w \\
u
\end{array}\right]
$$

where

$$
A=\left[\begin{array}{cc}
\boldsymbol{0} & \boldsymbol{I} \\
-M^{-1} P & -M^{-1} N
\end{array}\right] \quad B_{1}=\left[\begin{array}{cc}
\boldsymbol{0} & \boldsymbol{0} \\
M^{-1} D_{1} & M^{-1} D_{2}
\end{array}\right] \quad B_{2}=\left[\begin{array}{l}
\boldsymbol{0} \\
M^{-1} Q
\end{array}\right]
$$


$w=\left[\begin{array}{c}\dot{\psi}_{r} \\ \ddot{\psi}_{r}\end{array}\right] \quad u=\delta_{s w}$

$M=\left[\begin{array}{ccccccc}m_{1}+m_{2} & -m_{2} c & -m_{2} a_{2} & -m_{s 1} h_{1} & -m_{s 2} h_{2} & 0 & 0 \\ m_{s 1} h_{1} & -I_{x z 1} & 0 & -I_{x s 1} & 0 & 0 & 0 \\ m_{s 2} h_{2} & -m_{s 2} h_{2} c & -m_{s 2} h_{2} a_{2}-I_{x z 2} & 0 & -I_{x s 2} & 0 & 0 \\ m_{1} c & I_{z 1} & 0 & -m_{s 1} h_{1} c+I_{x z 1} & 0 & 0 & 0 \\ m_{2} a_{2} & -m_{2} a_{2} c & -m_{2} a_{2}^{2}-I_{z 2} & 0 & -I_{x z 2}-m_{s 2} h_{2} a_{2} & 0 & 0 \\ 0 & 1 & -1 & 0 & 0 & -1 & 0 \\ 0 & 0 & 0 & 0 & 0 & 0 & I_{s}\end{array}\right]$

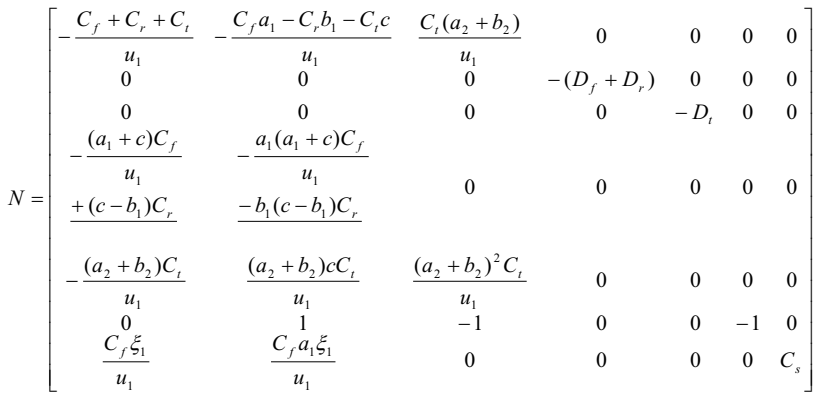

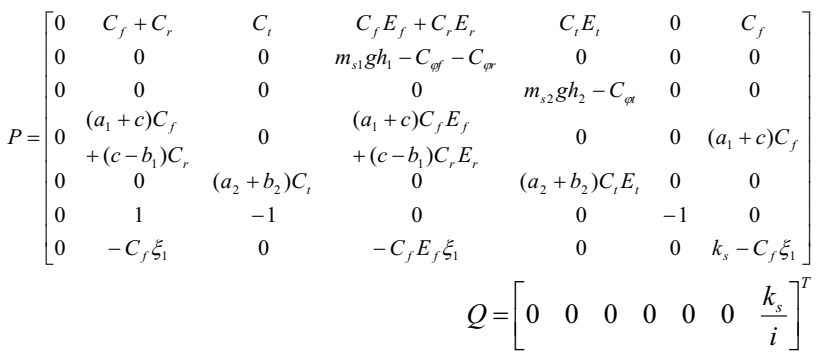

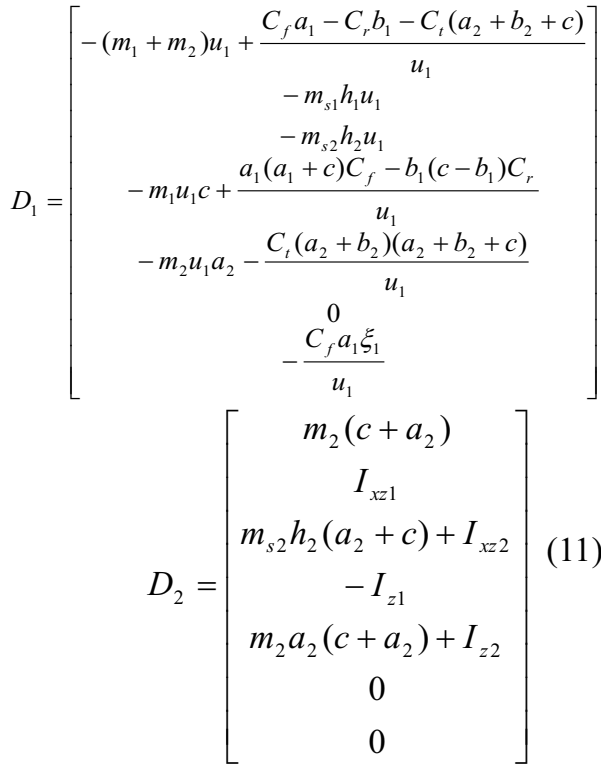

$A$ is 14 order matrix, $B_{1}$ is $14 \times 2$ order matrix, other factors will be determined. Designing $H_{\infty}$ robust controller can make use of (10).

\subsection{The analysis of transfer functions}

In the control generalized system by disturbance Fig.3, $G_{0}(s)$ is nominal controlled object, $K_{\mathrm{s}}$ is controller, $y$ is measuring output, interference signal $w$ is as the system disturbance input $d_{\mathrm{s}}$ which come from transfer function
$W(s)$, control output $z$ is same with the measuring output $y$ from system.

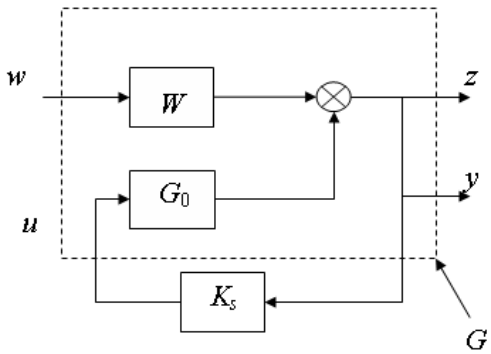

Figure 3. Diagram of generalized interference control system

From the Figure 3

$$
\left[\begin{array}{l}
z(s) \\
y(s)
\end{array}\right]=\left[\begin{array}{ll}
W(s) & G_{0}(s) \\
W(s) & G_{0}(s)
\end{array}\right]\left[\begin{array}{l}
w(s) \\
u(s)
\end{array}\right]=G(s)\left[\begin{array}{l}
w(s) \\
u(s)
\end{array}\right]
$$

so the transfer function matrix is

$$
G(s)=\left[\begin{array}{ll}
W(s) & G_{0}(s) \\
W(s) & G_{0}(s)
\end{array}\right]
$$

Setting $y_{d}$ as the look-ahead distance $d$ (meter) point offset, express as

$$
y_{d}=y_{r 1}+d \cdot \psi_{r 1}
$$

the transfer function $G_{0}(s)$ from input of steering wheel $\delta_{s w}$ to offset $y_{d}$ of target point is

$G_{0}(s)=\frac{Y_{d}(s)}{\delta_{s w}(s)}=G_{Y 1}(s)+d \cdot G_{\psi 1}(s)=C_{21}(s I-A)^{-1} B_{2}+d \cdot C_{22}(s I-A)^{-1} B_{2}$

where

$$
\begin{aligned}
& C_{21}=\left[\begin{array}{llllllllllllll}
1 & 0 & 0 & 0 & 0 & 0 & 0 & 0 & 0 & 0 & 0 & 0 & 0 & 0
\end{array}\right] \\
& C_{22}=\left[\begin{array}{llllllllllllll}
0 & 1 & 0 & 0 & 0 & 0 & 0 & 0 & 0 & 0 & 0 & 0 & 0 & 0
\end{array}\right]
\end{aligned}
$$

$$
\text { Transfer function } W(s) \text { of } w=\left[\begin{array}{l}
\dot{\psi}_{r} \\
\ddot{\psi}_{r}
\end{array}\right] \text { to } y_{d} \text { can }
$$
express like

$W(s)=\frac{Y_{d}(s)}{w(s)}=G_{Y 1}(s)+d \cdot G_{\psi 1}(s)=C_{11}(s I-A)^{-1} B_{1}+d \cdot C_{12}(s I-A)^{-1} B_{1}$

Because of that controlled output $z$ and measuring output $y$ from system is same, so that $\mathrm{C}_{11}=\mathrm{C}_{21}, \mathrm{C}_{12}=\mathrm{C}_{22}$. Putting the data from Appendix A table into (10), (15) and (18), look-ahead distance is 10 metter, and then the transfer function matrix (13) can be gotten.

\section{Design of $\mathrm{H} \infty$ loop shaping controller}

From McFarlane and Glover [3,4,5] use the steps of the designing of $H_{\infty}$ loop-shaping controller, we can obtain results of the loop-shaping and the controller calculates. 
Choosing $W_{1}=0.5 \frac{s+80}{s+2.8}, W_{2}=1$, through $M A T L A B$ robust and algorithm toolbox obtaining $\gamma=2.7812$ $(1<\gamma<10)$, making $\varepsilon_{\max }<1$, satisfy the goal of robust performance. ${ }^{[4,5,6]}$

Figure 4 is each singular value curve after shaping, we can see that after shaping the singular value curves of $W_{2} G_{0} W_{1}$ and open loop function $G_{0} K_{s}$ (red solid lines and red dotted line) are higher than $G_{0}$ (Black dotted line) in low frequency values, it shows that tracking capability and anti-low-frequency interference have improved with the use of controller. As the same time, $W_{2} G_{0} W_{1}$ singular value's slope of the curve is littler than $G_{0}$ (Curve is dropping fast) in high frequency, it means that after shaping the power to control noise is strengthen, slope of the $G_{0} K_{s}$ curve is same with nominal controlled object $G_{0}$, there is no weaken in control noise after shaping. The result of $\gamma$ is in a reasonable range, loop shaping is good to satisfy the robust stability's index.

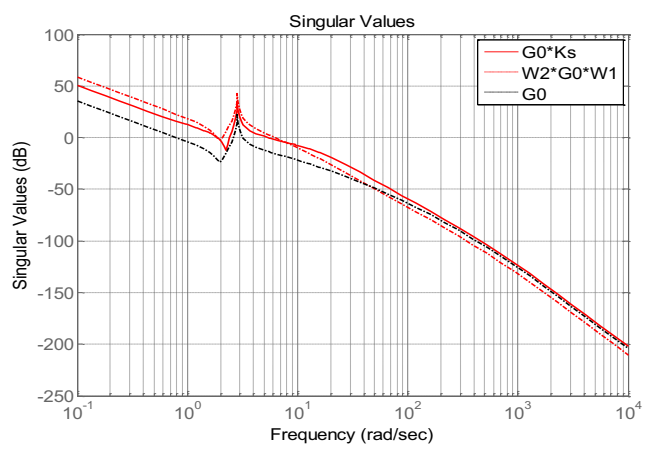

Figure 4. Singular values

The order of positive feedback controller $K_{\mathrm{s}}$ which is original obtained in this paper is 13. It is not good for application in engineering when order is too high. Therefore, we choose Hankel norm approximation method for model to reduced order. ${ }^{[7][8]}$

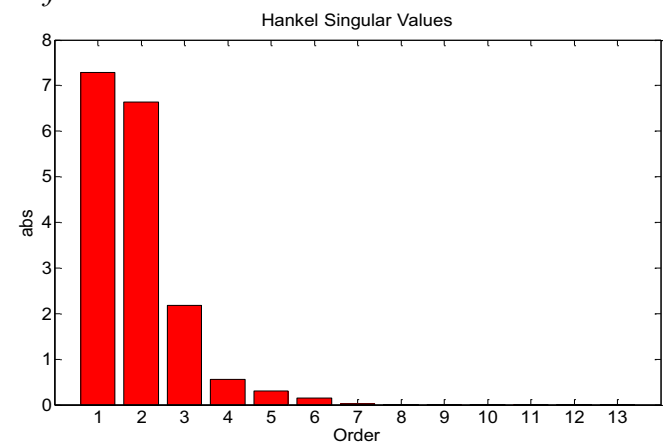

Figure 5. Hankel singular values

Figure 5 shows that the obtaining Hankel singular values which use this algorithm, abscissa represents original controller system order, ordinate represents singular value or "state energy" in every order, bigger "state energy" means that additional error $\left\|K_{s}-\hat{K}_{s}\right\|_{\infty}$ is bigger. Finally, 7 reduced-order controller is chosen, additional error is 0.0298 , controller is

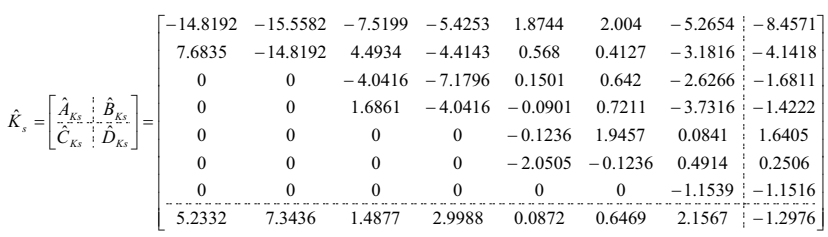

\section{Simulation of tractor-semitrailer route tracking control}

\subsection{Routes designing}

Thinking that widths of road and tractor-semitrailer, when tractor-semitrailer driving, lateral offset is better not more than 0.2 to 0.3 meters $^{[2]}$. So, tractor-semitrailer's control goal is to let vehicle system drive in the road, if it appears lateral deviation, controller should ensure that lateral offset is not beyond the required range. According to control objectives, it structures a driving route that it is continuous multi-curves, the designing route shows in Figure 6. Assuming that tractor-semitrailer drives in 500 meters road with constant advance speed, then goes to curvature radius of 600 meters' circular route which has three sections respectively, then, driving out along 500 meters straight. In the total route, steering wheel keeps zero degree firstly, and then changes three times, at last zero again.

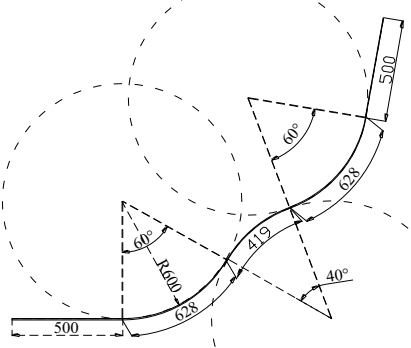

Figure 6. The route of tractor-semitrailer

\subsection{Simulate analysis of route tracking control}

Figure 7 shows the closed-loop control system of tractorsemitrailer, yaw rate and yaw angular acceleration can be considered as disturbance input in corners. The lateral offset which is 10 meters look-ahead of vehicle can be considered as controllable output. Steering angle initial input of in tractor-semitrailer is set to 0 , constant velocity is $60 \mathrm{~km} / \mathrm{h}$ or $16.67 \mathrm{~m} / \mathrm{s}$, the initial value of disturbance input $\dot{\psi}_{r}$ is $0.028(1 / \mathrm{s})$ and $\ddot{\psi}_{r}$ is also setting to 0.028 $\left(1 / \mathrm{s}^{2}\right)\left(\dot{\psi}_{r}=u / r_{0} \approx u_{1} / r_{0}\right)$. Times of each section of route are $30 \mathrm{~s}, 37.67 \mathrm{~s}, 25.1 \mathrm{~s}, 37.67 \mathrm{~s}$ and $30 \mathrm{~s}$. 


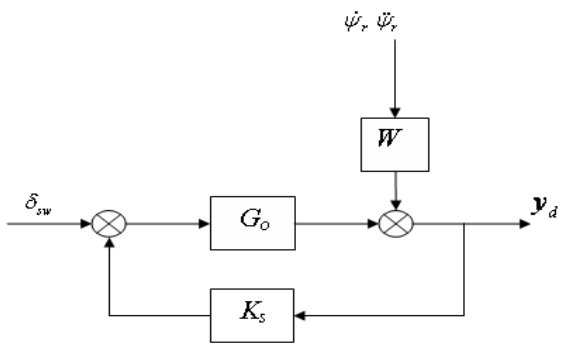

Figure 7. Implementation of the controller

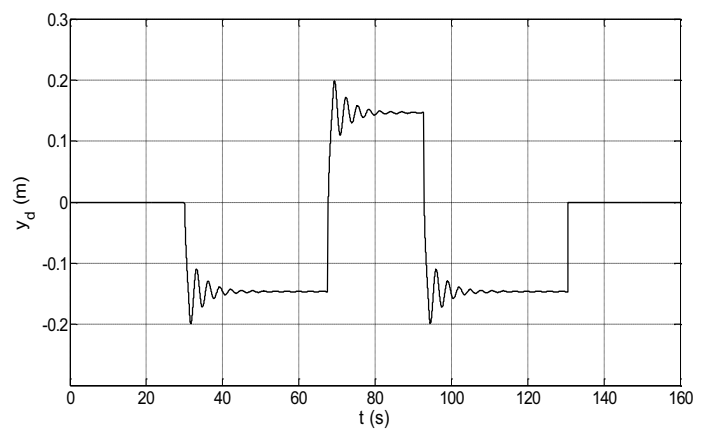

Figure 8. Lateral tracking offset simulation

Figure 8 shows that maximum vibration amplitude of lateral offset is limited in $0.2 \mathrm{~m}$ and can have stable value at least under the controller. Simulation results show that the tractor-semitrailer closed-loop system has the required robust with the help of controller, and it can keep the robust steady.

\section{Conclusions}

Tractor-semitrailer model which include DOF of body roll is described in road reference coordinate system as generalized controlled object. $H_{\infty}$ loop-shaping robust controller is designed and the order of the controller is reduced which could make the tractor-semitrailer stable under perturbed conditions and could guarantee the lookahead lateral offset keeping in the satisfied range.

\section{Acknowledgments}

The Education Department of Heilongjiang Province Youth Academic backbone support project(1253G056), Jiamusi University research project (L2011-015).

\section{References}

1. Sheng CHANG, Hong-guo XU and Hong-fei LIU. Journal of Jilin University (Engineering and Technology Edition). in Chinese.Vol. 6, p.1571-1576, (2011)

2. Jeng-Yu WANG, MASAYOSHI TOMIZUKA. Dynamic Analyses and Robust Steering Controller Design for Automated Land Guidance of Heavy-duty Vehicles. Asian Journal of Control, Vol.3, p.140-154, (2000)

3. Mcfarlane, D.C. and K.Glover.An $H_{\infty}$ design procedure using robust stabilization of normalized coprime factors. Proceedings of the 27th Conference on Decision and Control, Austin, Texas, p.13431348,(1988)

4. Mcfarlane, D.C. and K.Glover. Robust Controller Design using Normalised Coprime Factor Plant Descriptions: Springer Verlag, Lecture Notes in Control and Information Sciences. Vol.138, (1989)

5. DUNCAN MCFARLANE, KEITH GLOVER. A Loop Shaping Design Procedure Using Ho Synthesis. IEEE Transactions on Automatic Control ,Vol.37, p.759-769, (1992)

6. ZHOU, K., J.C. DOYLE.Essentials of Robust Control. NY: Prentice-Hall,(1998)

7. Safonov M.G., R.Y. CHIANG, and D.J.N. Limebeer: Optimal Hankel Model Reduction for Nonminimal Systems. IEEE Trans. On Automat. Contr. Vol. 35, p.496-502, (1990)

8. Glover, K.. All Optimal Hankel Norm Approximation of Linear Multivariable Systems and Their $L_{\infty}$-error Bounds[J].Int. J. Control, 39(6):1145$1193,(1984)$ 